\title{
STRATEGI MANAJEMEN KONFLIK DIMASA PANDEMI COVID- 19 MAHASISWA KEPERAWATAN KOTA MAKASSAR
}

\section{1| Kristan, 2| Nur Hidayah, 3| Muhammad Farid Abidin}

Email : kristan@binus.ac.id

ABSTRACT
Awareness in conflict management is very important for learners to consider. Students, as
one of the largest numbers of people in educational institutions, have undoubtedly felt the
effects of the Covid-19 crisis, where the learning environment, which is normally carried
out face-to-face both on campus and in the field of practice, has turned online. Conflict is
unavoidable, but it can be handled in such a way that it has a positive effect as a lesson.
Growing knowledge of conflict management is one way of avoiding conflict. Conflict,
depending on how the conflict is handled, can be negative (detrimental) but can be
constructive (beneficial). The aim of this study was to identify the conflict management
strategies of students of the nursing profession in the city of Makassar during the Covid-19
pandemic. The methodology in this study uses quantitative methods with a descriptive
frequency distribution analysis style. The results of this research show that nursing
students have a 100\% conflict management strategy on a partnership strategy, then
$94.6 \%$ on a compromise strategy, 93.9\% on an avoidance strategy, 92.5\% on an
accommodation strategy, and $91.8 \%$ on a competition strategy. With the result that a
collaborative conflict management approach is used by the prevailing conflict
management strategy used by nursing career students in the town of Makassar.

ARTICLE INFO

Keywords:
Conflict management strategies;
Student nurses; Covid-19

DOI:

$\underline{10.24252 / \text { kesehatan.v13i2.17754 }}$

\section{Pendahuluan}

Pengetahuan tentang manajemen konflik sangat penting untuk diketahui oleh mahasiswa. Mahasiswa merupakan generasi muda calon pencerah sekaligus pelaku kehidupan bermasyarakat dan bernegara untuk kehidupan yang akan datang. Dalam kehidupan kampus, mahasiswa sebagai suatu komunitas akademis memiliki latar belakang kehidupan yang unik dan majemuk (multicultural). Hal ini dapat dilihat dari segi sosiokultul (asal daerah), ekonomi, agama, dialek, maupun karakter khas.

Saat ini, seluruh dunia digegerkan oleh wabah penyakit yang dikenal dengan nama COVID-19. Penyakit ini merupakan penyakit pernapasan akut yang disebabkan oleh sebuah novel coronavirus (SARS-CoV-2, atau dikenal dengan nama COVID-19), yang menyebabkan kematian dan dominan pada orang yang berusia $\geq 60$ tahun dan pada orang yang mempunyain riwayat medis seperti penyakit kardiovaskular, penyakit pernapasan kronis, diabetes dan kanker (1). Maraknya wabah penyakit ini mengakibatkan masyarakat diseluruh dunia mengalami kepanikan dan mengakibatkan adanya gangguan psikologis bagi masyarakat. Dengan maraknya penyakit tersebut membuat pemerintah menerapkan program Pembatasan Sosial Berskala Besar (PSBB) yang dianggap mampu mempercepat penanggulangan sekaligus mencegah penyebaran covid-19 ini yang semakin meluas.

Respons yang diperlukan, seperti isolasi sosial, anjuran untuk tetap berada dirumah, karantina seluruh masyarakat, dan penutupan instansi pendidikan telah mengubah kehidupan sehari-hari secara tiba-tiba. Mahasiswa sebagai salah satu individu yang jumlahnya paling banyak di institusi pendidikan tentunya sangat merasakan dampak pendemi Covid-19, dimana sistem pembelajaran yang biasanya dilakukan secara tatap muka baik di lingkungan kampus ataupun lahan praktek berubah menjadi daring. Dalam hal ini pelajar atau mahasiswa mendapatkan masalah baru dalam penyelesaian tugas baik itu tugas personal atau kelompok akibat penerapan strategi ini, belum lagi dengan masalah koneksi jaringan yang tidak stabil pada tiap daerah masing-masing mahasiswa. Dengan sistem pembelajaran baru ini yang dapat menjadi potensi terjadinya konflik baik itu interpersonal, ataupun intergroup. Kondisi tersebut juga menghadapkan Dosen sebagai pendidik dilingkungan perguruan tinggi pada tantangan dan masalah bagaimana mencari cara yang terbaik untuk menyampaikan pesan materi perkuliahan kepada para mahasiswa.

Konflik menjadi sesuatu yang tidak dapat di hindari karena tujuan, kebutuhan, tanggung jawab, dan nilai yang dimiliki pada individu atau organisasi berbeda dalam setiap persepsi, perbedaan 
itulah yang bisa menjadi salah satu penyebab terjadinya konflik (2). Menurut Ana (2012) (3) menyatakan bahwa konflik terjadi disebabkan karena: adanya perbedaan interpersonal pada setiap dimensi-umur, jenis kelamin, ras, pandangan, perasaan, pendidikan, pengalaman, tingkah laku, pendapat, budaya, kebangsaan, keyakinan, dll, serta perbedaan kepentingan dalam hubungan antar manusia karena perbedaan budaya, posisi, peran, status, dan tingkat hirarki. Konflik dalam kehidupan sehari-hari adalah sesuatu hal yang sangat biasa terjadi. Sepanjang seseorang masih hidup hampir mustahil untuk menghilangkan konflik.

Konflik memang tidak bisa dihindari, melainkan dapat dikelola agar memberikan dampak positif sebagai sebuah pembelajaran. Konflik antar perorangan dan antar kelompok merupakan bagian dari sejarah umat manusia. Berbagai macam keinginan seseorang, perbedaan pandangan, dan tidak terpenuhinya keinginan tersebut dapat berakhir dengan konflik. Salah satu cara mencegah terjadinya konflik ialah dengan meningkatkan pengetahuan manajemen konflik. Konflik dapat bersifat negatif (merugikan) tetapi dapat bersifat positif (menguntungkan), tergantung bagaimana konflik dikelola.

Menciptakan penyelesaian konflik yang kreatif merupakan strategi manajemen konflik yang efektif. Konflik berdampak baik ataupun buruk tergantung pada pengelolaan konflik sendiri. Perubahan sistem pendidikan dimasa covid-19 mengubah secara drastis sistem pendidikan pada mahasiswa keperawatan yang sebelumnya melakukan praktik secara nyata di rumah sakit menjadi praktik melalui media online atau secara daring. Hal ini menimbulkan banyak masalah baik itu berupa kecemasan, stress bahkan depresi dari perubahan sistem tersebut di masa pandemic covid-19 ini.

\section{Metode Penelitian}

Penelitian ini menggunakan metode kuantitatif dengan desain Deskriptif Analisis Distribusi Frekuensi untuk mengetahui strategi manajemen konflik yang digunakan oleh mahasiswa profesi ners di kota makassar. Instrumen yang digunakan dalam penelitian menggunakan kuesioner yaitu Rahim Organization Conflict Inventory (ROCI) untuk mengukur tingkat pengetahuan mahasiswa profesi ners tentang strategi manajemen konflik yang ada. Analisis data pada penelitian ini yaitu analisis univariat dengan mendeskripsikan variabel melalui tabel distribusi frekuensi dan presentase.

\section{Hasil Penelitian}

\section{Karakteristik responden}

Tabel 1. Karakteristik Responden

\begin{tabular}{lcc}
\multicolumn{1}{c}{ Variabel } & Frekuensi (n) & Presentasi(\%) \\
\hline Jenis Kelamin: & 61 & \\
Laki-laki & 86 & $51.5 \%$ \\
Perempuan & & $58.5 \%$ \\
\hline Usia: & 11 & $7.5 \%$ \\
20 Tahun & 30 & $20.4 \%$ \\
21 Tahun & 48 & $32.7 \%$ \\
22 Tahun & 24 & $16.3 \%$ \\
23 Tahun & 27 & $18.4 \%$ \\
24 Tahun & &
\end{tabular}




\begin{tabular}{lcc} 
25 Tahun & 7 & $4.8 \%$ \\
\hline Masa praktik: & 35 & \\
1-4 Bulan & 45 & $23.8 \%$ \\
4-8 Bulan & 67 & 30.65 \\
8-12 Bulan & $\mathbf{1 4 7}$ & $45.6 \%$ \\
\hline \multicolumn{1}{c}{ Total } & $\mathbf{1 0 0 \%}$ \\
\hline
\end{tabular}

Sumber, Data Primer 2020

Berdasarkan tabel 1. di atas dapat diketahui bahwa jumlah responden mahasiswa profesi yang paling banyak adalah perempuan sebanyak 86 orang $(58,5 \%)$ sedangkan laki-laki 61 orang $(41,5 \%)$. Berdasarkan usia didapatkan usia 20 tahun sebanyak 11 responden (7.5\%), 21 tahun sebanyak 30 responden (20.4\%), 22 tahun sebanyak 48 responden (32.7\%), 23 tahun sebanyak 24 responden (16.3\%), 24 tahun sebanyak 27 responden (18.4\%) dan 25 tahun sebanyak 7 responden (4.8\%). Berdasarkan masa praktik didapatkan 1-4 bulan sebanyak 35 orang $(23,8 \%)$, 4-8 bulan sebanyak 45 orang (30.6\%) dan 8-12 bulan sebanyak 67 orang (45.6\%).

\section{Strategi Manajemen Konflik Mahasiswa Profesi Ners}

Tabel 2. Distribusi Frekuensi Responden Terhadap Strategi Manajemen Konflik Mahasiswa Profesi Ners

\begin{tabular}{ccccccc}
\hline \multirow{2}{*}{ Strategi } & \multicolumn{3}{c}{ Frekuensi } & & \multirow{2}{*}{ Total } \\
\cline { 2 - 6 } & \multicolumn{3}{c}{ Ya } & \multicolumn{2}{c}{ Tidak } & \\
\cline { 2 - 6 } & $\mathbf{n}$ & $\%$ & $\mathbf{n}$ & $\%$ & $\mathbf{n}$ & $\%$ \\
\hline Kolaborasi & 147 & $100 \%$ & - & - & 147 & $100 \%$ \\
\hline Akomodasi & 136 & $92.5 \%$ & 11 & $7.5 \%$ & 147 & $100 \%$ \\
\hline Kompetisi & 135 & $91.8 \%$ & 12 & $8.2 \%$ & 147 & $100 \%$ \\
\hline kenghindar & 138 & $93.9 \%$ & 9 & $6.1 \%$ & 147 & $100 \%$ \\
\hline
\end{tabular}

Sumber, Data Primer 2020

Tabel diatas menunjukan bahwa mahasiswa profesi ners memiliki strategi manajemen konflik $100 \%$ pada strategi kolaborasi, selanjutnya $94.6 \%$ pada strategi kompromi, $93.9 \%$ pada strategi menghindar, $92.5 \%$ pada strategi akomodasi dan $91.8 \%$ pada strategi kompetisi.

\section{Diskusi}

\section{Karakteristik Responden}

Pada penelitian ini diperoleh responden berjenis kelamin perempuan sebanyak 86 orang dan responden berjenis kelamin laki-laki sebanyak 61 orang Berdasarkan hal tersebut dapat dikatakan bahwa responden mayoritas perempuan. Kalendesang (2017) (4) mengatakan bahwa mayoritas perawat perempuan rentan mengalami konflik karena beban kerja dan juga peran ganda yang dialami perawat perempuan cukup tinggi dibanding perawat laki-laki.

Berdasarkan hasil analisis usia responden, dapat dilihat bahwa usia responden terbanyak terdapat pada usia 20-22 tahun sebanyak 89 orang Dalam penelitian Tenggor (2019) (5) mengatakan bahwa responden usia muda perawat rentan mengalami kelelahan kerja akibat 
pola tidur yang tidak teratur dan keadaan tersebut dapat memcu terjadinya konflik pada perawat. sedangkan responden dengan usia terendah terdapat pada usia 23-25 sebanyak 58 orang.

Berdasarkan hasil analisis mengenai masa kerja responden dapat dilihat bahwa mayoritas responden mahasiswa profesi ners di Kota Makassar memiliki masa praktik terbanyak selama 8 s.d 12 Bulan sebanyak 67 orang atau 45,6 \%. Perawat yang memiliki masa kerja yang lama memiliki banyak pengalaman bekerja, sehingga telah banyak melewati dan mengetahui fasefase konflik kerja perawat di rumah sakit. Rosyad (2017) (6) sedangkan responden dengan masa praktik terendah terdapat pada masa praktik 1 s.d 4 Bulan sebanyak 35 orang.

\section{Manajemen Strategi Konflik pada mahasiswa profesi Ners}

Berdasarkan hasil penelitian dari 147 responden mahasiswa profesi ners yang mengisi form kuisioner online Rahim Organizational Conflict Inventory (ROCI) II, dengan 28 pernyataan untuk kuisioner ROCI yang digunakan sebagai penilaian terhadap teman sejawatnya didapatkan hasil bahwa mayoritas responden memilih strategi manajemen konflik kolaborasi $(100 \%)$, strategi akomodasi, $92,5 \%$ strategi menghindar 93,9\%, 91.8\% pada strategi kompetisi dan $94.6 \%$ pada strategi kompromi. Pernyataan "Saya mencoba menyelidiki suatu masalah bersama teman sejawat saya untuk menemukan solusi yang dapat kami terima " pada strategi kolaborasi mayoritas responden memilih skor tertinggi yaitu 5 (sangat setuju) dengan total skor 631 . Berdasarkan data di atas, secara umum strategi manajemen konflik mahasiswa profesi ners di kota Makassar mayoritas memilih kolaborasi.

Penelitian yang dilakukan oleh Ebrahim et al. (2014) (7) dengan judul penelitian Managers ' Conflict Management Styles and its Effect on Staff Nurses ' Turnover Intention at Shebin El Kom Hospitals, Menoufiya Governorat menggunakan kuisioner yang sama yaitu Rahim Organizational Conflict Inventory (ROCI) didapatkan hasil bahwa strategi manajemen konflik yang digunakan oleh staf perawat adalah strategi kolaborasi, sedangkan manajer perawat lebih dominan menggunakan strategi kolaborasi kemudian menghindar.

Menurut Sinskey et al. (2019) (8) menjelaskan bahwa penerapan strategi manajemen konflik pada strategi konflik kolaborasi lebih banyak meluangkan waktu untuk berdiskusi, saling memahami masing-masing sudut pandang yang diberikan sehingga menemukan solusi yang integrative. Serupa dengan peneitian yang dilakukan Daniyanti \& Kamal (2016) (9) menjelaskan bahwa strategi kolaborasi mampu memberikan dampak positif bagi kedua pihak yang berkonflik, karena strategi ini memberikan ruang untuk diskusi terbuka sehingga tidak ada pihak yang merasa di rugikan.

Hasil yang didapatkan dalam penelitian Saeed Ahmad (2018) (10) mengenai program pembinaan konflik yang diberikan oleh perawat melaporkan bahwa strategi manajemen konflik tertinggi yang di pilih oleh perawat sebelum diberikan program pembinaan konflik adalah kolaborasi dengan nilai mean $(2,00)$, pada saat diberikan program hasil yang didapatkan juga kolaborasi dengan nilai mean $(21,98)$. selanjutnya setelah di berikan program juga melaporkan strategi manajemen konflik tertinggi masih kolaborasi $(10,70)$.

Hasil penelitian Inrahim (2018) (11) melaporkan bahwa dari 20 responden perawat di rumah sakit El-Gharbia sebelum diberikan program edukasi manajemen konflik didapatkan hasil strategi manajemen konflik kolaborasi mayoritas di pilih oleh perawat dalam menangani konflik yang ada. Hal ini ditunjukkan dengan presentasi kekuatan straegi kolaborasi yang digunakan dalam penelitian ini sebesar 9\%. Strategi manajemen konflik kolaborasi dominan digunakan sebab strategi ini mengupayakan solusi menang-menang terhadap dua belah pihak dengan jalan bekerja yang berbeda. Huang (2010) dalam penelitian Miftahun (2013) (12) mengatakan bahwa startegi kolaborasi banyak digunakan karena dalam strategi ini ada tiga jenis pendekatan yang dapat digunakan dalam mengaplikasikan strategi ini, antara lain kooperatif, kompetitif dan menghindar. 
Penelitian yang dilakukan oleh Ahanchian (2015) (13) di salah satu rumah sakit di Iran, meskipun kelima strategi manajemen konflik digunakan oleh perawat di ruangan perawatan kritis, akan tetapi didapatkan hasil bahwa strategi kolaborasi yang paling sering digunakan diantara 5 strategi manajemen tersebut. Hasil yang serupa juga didapatkan pada penelitian Bikmoradi et al. (2017) (14) didapatkan hasil bahwa secara keseluruhan 52,2\% manajer perawat dan perawat menggunakan strategi pemecahan masalah kolaborasi dan akomodasi, diikuti dengan penggunaan strategi tidak konfrontasional yaitu penghindaran dan kompromi.

Selanjutnya penelitian, yang dilakukan oleh Leveillee (2018) (15) mengeksplorasi pengalaman manajemen konflik perawat bedah menunjukan bahwa ada pengaruh konsep gender dalam penentuan srategi manajemen konflik oleh perawat hal di dukung dengan mayoritas perawat dalam penelitian tersebut memilih startegi kolaborasi dibanding laki-laki. Hal ini dikatakan bahwa perempuan cenderung mendukung aspek pribadi dengan menginginkan harmonisasi secara universal.

Kemudian, analisis strategi manajemen konflik yang menjadi strategi tertinggi, menggunakan kuisioner terdiri atas 7 butir pernyataan dengan skor 1-5 yaitu angka semakin rendah untuk pernyataan tidak setuju dan angka semakin tinggi untuk pernyataan setuju. Pernyataan pertama yaitu pernyataan nomor (28) "Saya mencoba untuk bekerja sama dengan atasan saya untuk pemahaman yang tepat terhadap suatu masalah" mendapatkan total skor 626.

Dari hasil penelitian-penelitian sebelumnya bahwa strategi mekanisme konflik yang dominan digunakan oleh mahasiswa keperawatan maupun perawat yang bekerja di instansi kesehatan lebih cenderung menggunakan strategi kolaborasi.

\section{Kesimpulan}

Berdasarkan hasil penelitian didapatkan bahwa strategi manajemen konflik yang dominan digunakan oleh mahasiswa profesi ners di kota makassar yaitu menggunakan strategi manajemen konflik kolaborasi.

\section{Daftar Pustaka}

1. Organization WH. Infection Prevention and Control Quidance for Long-Term Facilities in the Context of COVID-19. 2020; March 1-5.

2. Kim WS, Nicotera AM, McNulty J. Nurses' perceptions of conflict as constructive or destructive. J Adv Nurs. 2015;71(9):2073-83.

3. Ana S. Conflict Leadership : Navigating Toward Effective and Efficient Team Outcomes. J Qual Particip. 2012;35(2):25-30.

4. Kalendesang PM, Bidjuni H, Malara TR. Hubungan Konflik Peran Ganda Perawatwanita Sebagai Care Giver Dengan Stres Kerja Di Ruangan Rawat Inap Rumah Sakit Jiwa Prof. Dr.V.L.Ratumbuysang Provinsi SULAWESI UTARA. e-Journal Keperawatan. 2017;5.

5. Tenggor D, Pondaag L, Hamel SR. Faktor-Faktor Yang Berhubungan Dengan Kelelahan Kerja Pada Perawat Di Ruang Rawat Inap Rumah Sakit Umum Gmim Pancaran Kasih Manado. eJournal Keperawatan (e-Kp). 2019;7.

6. Rosyad, Sabella A, Agus S. Hubungan Konflik Peran Ganda (Work Family Conflict) Terhadap Stres Kerja Perawat Wanita Di Ruang Rawat Inap, Intensive Care dan IGD RSUD Tugurejo Semarang. 2017;

7. Ebrahim M, El A, Keshk LI. Managers ' Conflict Management Styles and its Effect on Staff Nurses ' Turnover Intention at Shebin El Kom Hospitals , Menoufiya Governorate. World J Med Sci. 2014;11(1):132-43.

8. Jina L. Sinskey M, Joyce M. Chang M, Gail S. Shibata M, Andrew J. Infosino M, Kathryn Rouine-Rapp M. Applying Conflict Management Strategies to the Pediatric Operating Room. Anesth Analg. 2019;129(4):1109-17.

9. Daniyanti M, Kamil H. Conflict Management and Job Satisfaction of the Nurses in the Public Hospital dr. Zainoel Abidin Banda Aceh. 2016;1-7.

10. Saeed Ahmed Abd-Elrhaman E. The Effect of Conflict Management Program on Quality of 
Patient Care. Am J Nurs Sci. 2018;7(5):192.

11. Ibrahim SA. The Effect of Conflict-Management Enhancing Strategy for Head Nurses on the Quality of Vertical Dyad Linkage with Nurses. Int J Nurs Didact. 2018;08(04):25-34.

12. Miftahun A, Kistyanto A. Peran Moderasi Manajemen Konflik Kolaborasi Pada Hubungan Konflik Tugas Dan Konflik Hubungan. 2013;1.

13. Ahanchian MR, Zeydi AE, Armat MR. Conflict management styles among Iranian critical care nursing staff: A cross-sectional study. Dimens Crit Care Nurs. 2015;34(3):140-5.

14. Bikmoradi A, Abdi F, Soltanian A-R, Hamidi Y. The Correlation Between Conflict Management Style and Nurse Managers' Demographic Characteristics in Hamadan Therapeutic and Educational Centers. Sci J Hamedan Nurs Midwifery Fac. 2017;25(2):2735.

15. Leveillee GM. Exploration of Conflict Management Styles Used by MedicalSurgical Nurses. 2018; 


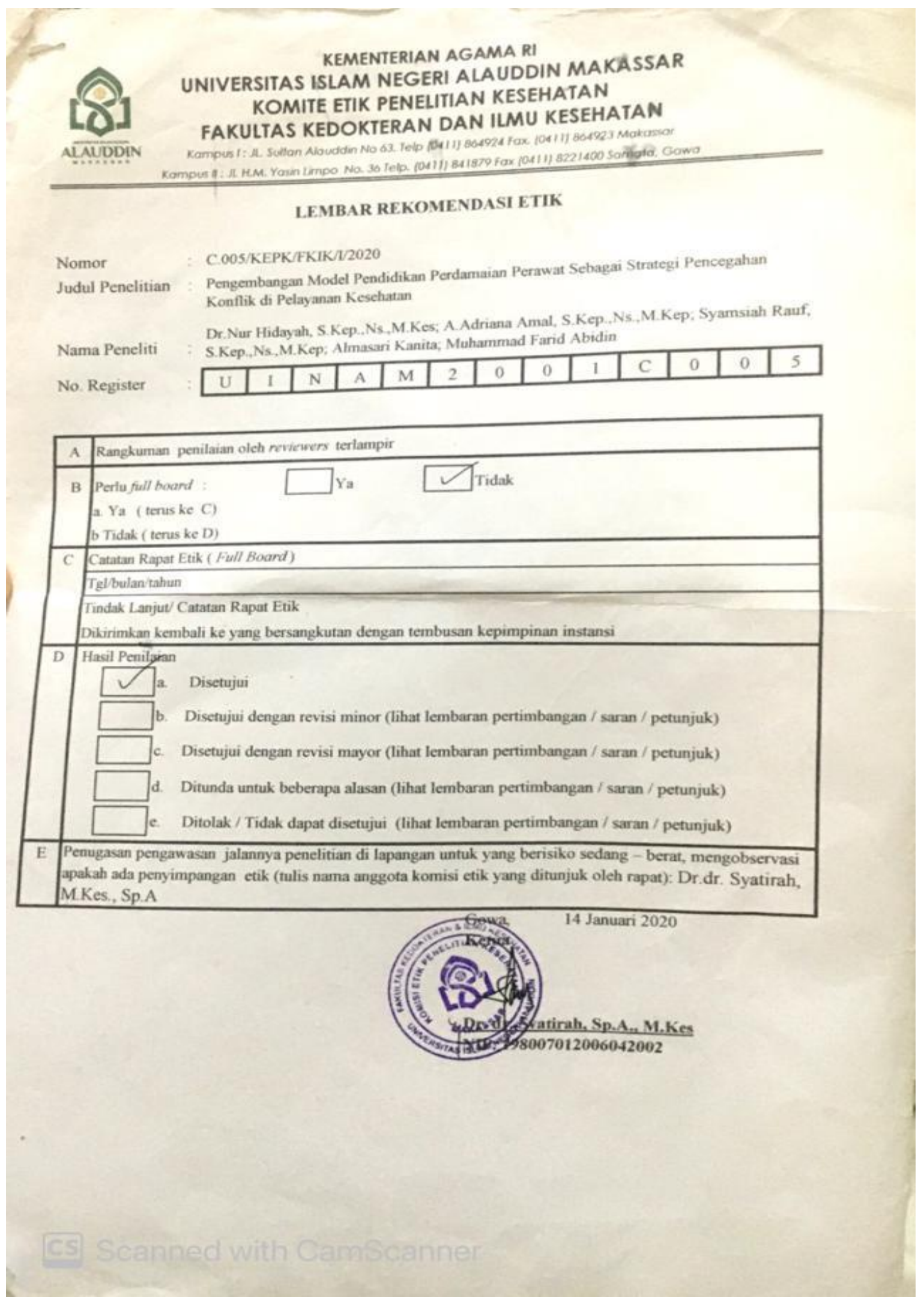

Figure 1 Lampiran Rekomendasi Kode Etik 